\title{
Epigenetic mechanisms leading to overexpression of HMGA proteins in human pituitary adenomas
}

\author{
Daniela D'Angelo ${ }^{1 *}$, Francesco Esposito ${ }^{1}$ and Alfredo Fusco ${ }^{1,2}$ \\ ${ }^{1}$ Dipartimento di Medicina Molecolare e Biotecnologie Mediche, Istituto per l'Endocrinologia e l'Oncologia Sperimentale del \\ CNR, Università degli Studi di Napoli "Federico II", Naples, Italy, ${ }^{2}$ Instituto Nacional de Câncer - INCA, Rio de Janeiro, Rio de \\ Janeiro, Brazil
}

OPEN ACCESS

Edited by:

Stefano La Rosa,

Ospedale di Circolo, Italy

Reviewed by:

Rosa Marina Melillo,

University of Naples Federico II, Italy

Silvia Uccella,

University of Insubria, Italy

*Correspondence:

Daniela D'Angelo,

Istituto per l'Endocrinologia e

l'Oncologia Sperimentale del CNR,

Via Pansini 5, Naples 80131, Italy

daniela.dangelo@unina.it

Specialty section:

This article was submitted to

Pathology, a section of the journal

Frontiers in Medicine

Received: 10 April 2015

Accepted: 23 May 2015

Published: 08 June 2015

Citation:

D'Angelo D, Esposito $F$ and Fusco $A$

(2015) Epigenetic mechanisms

leading to overexpression of HMGA

proteins in human pituitary adenomas.

Front. Med. 2:39.

doi: 10.3389/fmed.2015.00039
Overexpression of the high-mobility group A (HMGA)1 and HMGA2 proteins is a feature of all human pituitary adenoma (PAs) subtypes. However, amplification and/or rearrangement of the HMGA2 have been described in human prolactinomas, but rarely in other pituitary subtypes, and no genomic amplification of HMGA1 was detected in PAs. Here, we summarize the functional role of HMGA proteins in pituitary tumorigenesis and the epigenetic mechanisms contributing to HMGA overexpression in these tumors focusing on recent studies indicating a critical role of non-coding RNAs in modulating HMGA protein levels.

Keywords: HMGA proteins, pituitary tumors, microRNAs, long non-coding RNA, pseudogenes

\section{Introduction}

Pituitary tumors account for up to $25 \%$ of all diagnosed human brain tumors and the estimated prevalence rate in the general population is about $17 \%$ (1). They can be classified in different ways depending upon their size, radiographic appearance, endocrine function, morphology, and cytogenesis. Based on the invasiveness, they are divided into (a) benign adenomas, representing the majority of pituitary tumors that grow slowly, and rarely go toward the malignant phenotype; (b) invasive adenomas, benign tumors that may spread to bones of the skull or the sinus cavity below the pituitary gland; (c) pituitary carcinomas, which are malignant and spread into other areas of the central nervous system (brain and spinal cord) or outside of the central nervous system. They are extremely rare (2).

According to their size, pituitary adenomas (PAs) are classified into microadenomas $(<10 \mathrm{~mm}$ in diameter), macroadenomas $(>10 \mathrm{~mm})$, and giant adenomas $(>40 \mathrm{~mm})$.

On the basis of their endocrine activity, PAs can be distinguished in hormone producing or clinically non-functioning. About one-third of pituitary tumors are not associated with clinical hypersecretory syndromes and they are called non-functioning pituitary adenomas (NFPAs). Hormone-producing PAs release active hormones in excessive amounts into the bloodstream and they are currently classified into five main immunohistochemistry (IHC) types: prolactinoma (PRL, 25-41\%) somatotroph adenomas (GH, 10-15\%), corticotroph adenomas (ACTH, about 10\%), thyrotroph adenomas (TSH, $<1 \%$ ), and gonadotroph adenomas (FSH-LH $<1 \%$ ), which can be monohormonal or plurihormonal, with or without signs of hypersecretion (3).

Pituitary tumorigenesis is generally considered as a model of the multistep process of tumorigenesis, in which molecular alterations represent the initializing event that transforms cells and hormones and/or growth factors promote cell proliferation (1). Activation of oncogenes or loss of tumor-suppressor genes, as well as alteration of cell cycle mediators and epigenetic modifications, have been frequently reported to be involved in the pathogenesis of PAs (4). 
The great majority of PAs arise in a sporadic manner, and only a minority of them is part of hereditary or familial syndromes. The majority of adenomas arising in hereditary syndromes are $\mathrm{GH}$-secreting adenomas and they are associated to MEN-1 (linked to somatic mutations of the tumor-suppressor gene MEN-1), Carney's complex (CNC) (linked to mutations of the tumorsuppressor gene PRKAR1A), and McCune-Albright syndrome (linked to activating mutations of the $g s p$ oncogene). An activating mutation of the $g s p$ oncogene is the most frequent genetic alteration in sporadic tumors. It is a point mutation located in the alpha subunit of the G-protein (GNAS), a stimulatory protein of adenylylcyclase at the membrane level (5).

Pituitary tumor transforming gene (PTTG, also known as securin) has been also implicated in pituitary tumorigenesis. PTTG is largely expressed in functional human adenomas but not in normal pituitary tissue (6) and its overexpression in transgenic mice results in pituitary hyperplasia and adenoma formation (7). GADD $45 \gamma$ has been the first identified tumor-suppressor gene in pituitary tumorigenesis. GADD $45 \gamma$ is a negative regulator of cell growth and it is not expressed in the majority of functional and NFPAs (8). In addition, several animal models of cell cycle regulators, such as $\mathrm{pRB}, \mathrm{CDKs}$, or CKIs, have demonstrated that alterations of genes involved in cell cycle control are associated with the development of PAs (9). Indeed, mice carrying genetically modified alleles of the retinoblastoma $(\mathrm{Rb})$ tumor-suppressor gene, causing an increase in the E2F1 activity, showed high predisposition to develop pituitary tumors (10), and this occurs also in mice with impaired function of $\mathrm{p} 27$ or $\mathrm{p} 18$, both converging on pRB pathway $(11,12)$.

Recently, two different research groups have identified novel somatic mutations in the deubiquitinase gene USP8, all of them harboring in the 14-3-3 protein binding motif and its nearby region, in about one-third of corticotroph adenomas. These mutations enhanced the deubiquitinase catalytic activity of USP8, thus protecting its numerous targets, such as EGFR, from the lysosomal degradation and thereby leading to an enhanced activity of the EGFR pathway $(13,14)$.

\section{HMGA as Driver in the Development of Human Pituitary Adenomas}

The high-mobility group A (HMGA) family consists of four proteins, HMGA1a, HMGA1b, HMGA1c, encoded by HMGA1 gene through alternative splicing, and HMGA2, encoded by the homonymous gene. They are the most abundant non-histone chromosomal proteins, also known as "architectural transcriptional factors" since they do not possess a direct transcriptional activity, but alter the chromatin structure through their DNA-binding domains, called "AT hooks" (15), by which they bind the minor groove of DNA in AT-rich sequences regulating, positively or negatively, the transcription of several genes (16-18).

High-mobility group A proteins are expressed at high levels during embryogenesis and at low levels in adult tissues, whereas their expression is abundant in several human malignant neoplasias (19). HMGA proteins have a causal role in cell transformation. Indeed, their blocking by antisense methodologies inhibits retrovirally induced malignant transformation of rat thyroid cells (20) while their enforced overexpression induces a transformed phenotype (21), and transgenic mice overexpressing the HMGA proteins develop several benign or malignant neoplasias (22-24).

The involvement of the HMGA genes, HMGA2 in particular, in benign neoplasias has been widely reported. Rearrangements of the HMGA2 gene were observed in human benign tumors of mesenchymal origin, in which translocations involving the region 12q13-15 (where HMGA2 gene is located) have been frequently detected $(25,26)$.

The first evidences of the role of HMGA2 in pituitary tumorigenesis came from the observation that transgenic mice carrying the HMGA2 gene under the transcriptional control of the cytomegalovirus promoter developed PAs secreting prolactin and growth hormone (23), more frequently in females than in males. In addition, cytogenetic analysis of human prolactinomas revealed trisomy or tetrasomy of chromosome 12 associated with an amplification of the HMGA2 locus, which correlated with HMGA2 overexpression (27). Even though genomic amplification of the HMGA2 gene was rarely found in PAs other than prolactinomas (28), the overexpression of HMGA1 and HMGA2 has been reported in a significant number of PAs $(29,30)$. Moreover, the level of HMGA2 protein has been found positively correlated with tumor invasion and was significantly higher in grade IV than in grades I, II, and III adenomas. High levels of HMGA2 expression were more frequently detected in macroadenomas than in microadenomas and also significantly correlated with the proliferation marker Ki-67 (31).

The mechanism by which HMGA overexpression induces the development of PAs is the enhancement of the E2F1 activity (32). This mechanism is quite unique; although HMGAs bind to the $\mathrm{pRB} A / \mathrm{B}$ pocket domain, they do not compete with the E2F1 protein in $\mathrm{pRB}$ binding, but displace HDAC1 from $\mathrm{pRB} / \mathrm{E} 2 \mathrm{~F} 1$ complex, resulting in enhanced acetylation of both E2F1 and DNA-associated histones, thereby promoting E2F1 activation. The rescue of the adenomatous phenotype when transgenic mice overexpressing the HMGA2 gene were mated with E2F1 knockout mice confirmed the role of the enhanced E2F transcriptional activity in the onset of PAs in HMGA transgenic mice (32). Subsequent studies have demonstrated that HMGA1 and HMGA2 can also affect cell cycle by regulating CCNB2, coding for cyclin B2 (30). Indeed, HMGAs are able to directly regulate this gene at transcriptional level, and, consistently, cyclin B2 overexpression was found in human PAs with a significant correlation with HMGA expression. In addition, other mechanisms could be responsible for the oncogenic role of HMGA in pituitary. Among these, the increased expression of IL2 and its receptor in pituitary cells by HMGA (22), and/or induction of the AP-1 activity by enhancing the expression of the AP-1 members FRA1 and JunB (33) cannot be excluded. Moreover, the pituitaryspecific transcription factor Pit-1 (POU domain, class 1, transcription factor 1) was found overexpressed in PAs from Hmgalb and Hmga 2 transgenic mice. It has been also demonstrated that Pit-1 is positively regulated by HMGA protein and its overexpression positively correlates with that of HMGA also in human PAs (34). 


\section{Epigenetic Control of HMGA Protein Levels by Non-Coding RNAs}

Overexpression of HMGA1 and HMGA2 proteins is a feature of human PAs, and according to a crucial role of their overexpression in pituitary tumorigenesis, transgenic mice overexpressing either hmgal or hmga2 develop PAs (24). However, while HMGA2 gene rearrangement and/or amplification was found in a certain number of PAs $(27,28)$, no genomic alterations of the HMGA1 locus have been detected in PAs, even though overexpression of both HMGA proteins has been described $(30,35,36)$. Therefore, other mechanisms accounting for HMGA overexpression in these tumors might be envisaged. Recent studies indicated that both the HMGA genes can be modulated by a novel class of epigenetic regulators, known as non-coding RNAs (ncRNAs).

In the last 15 years, thanks to the advent of bioinformatic approaches examining the human transcriptome, it came up that about $70 \%$ of the genome is transcribed but only $2 \%$ of the human genome is translated into proteins (37). The remaining large proportion of DNA, initially referred to as "junk DNA," was found to be transcribed as ncRNAs.

Non-coding RNAs comprise multiple classes of RNA that are not transcribed into proteins but have been shown to regulate transcription, stability, or translation of protein-coding genes (38). They include microRNAs (miRNAs or miRs), tRNAs, rRNAs, small nuclear RNAs (snRNAs), and heterogeneous group of long non-coding RNAs (lncRNAs).

\section{miRNAs Targeting HMGA Proteins}

microRNAs are sncRNA molecules of about $22 \mathrm{nt}$, which induce gene silencing by suppressing protein synthesis or by mRNA degradation. To date, over 1,000 miRNAs have been identified in humans, which regulate about $60 \%$ of mammalian genes (39). Interestingly, each miRNA is able to target multiple mRNA and, in turn, each mRNA can be regulated by several miRNAs cooperatively.

microRNA-mediated repression of target gene occurs by perfect or imperfect complementarity with sequence motifs predominantly found within the $3^{\prime}$ untranslated regions (UTRs) of the target mRNAs (40). Altered expression of miRNAs has been associated with various human diseases, including cancer, in which they can act as "onco-miR" or "tumor-suppressor-miR" (41).

Recent studies indicate a critical role of miRNAs in regulation of HMGA expression. Indeed, reduced expression of let-7 is reported in about $42 \%$ of PAs and has been inversely correlated with HMGA2 expression and high-grade tumors (42). Subsequently, it has been demonstrated that miR-15, miR-16, miR-26, miR-196a-2, and let-7a, which target both the HMGA genes, are drastically downregulated in a panel of 41 human PAs of different histotypes, and their expression is inversely correlated with the HMGA expression. Moreover, enforced expression of the HMGAtargeting miRNAs reduces cell growth of $\mathrm{GH} 3$, a rat GH/PRL pituitary cell line, supporting their tumor-suppressor role (43). Accordingly, the analysis of a miRNA expression profile of GH adenomas versus normal pituitary has unveiled a set of miRNAs constantly deregulated in somatotroph tumors, comprising
miR-326, miR-432, and miR-570, targeting HMGA2, miR-34b, and miR-548c-3p both having HMGA1 and HMGA2 as targets, and miR-326 and miR-603 targeting E2F1. Their downregulation was also found in PRL and gonadotroph adenomas, suggesting that it represents a general event in pituitary tumorigenesis. Subsequent functional studies have confirmed the role of the downregulation of these miRNAs in tumor growth and cell cycle regulation. Indeed, a significant reduction of cell number and, accordingly, an increase in the G1 phase population and a decrease in the $S$ phase were observed after transfection with the HMGA-targeting miRNAs. Finally, an inverse correlation was found between miRNA expression and HMGA1 and HMGA2 protein levels in GHsecreting adenomas, suggesting a possible role of these miRNAs in the HMGA/E2F1 pathway, and thereby in the development of PAs (44). Recently, it has been reported that also miR-23b, which was found downregulated in $\mathrm{GH}$, gonadotroph, and null cell PAs, targets HMGA2, and that its overexpression inhibits cell proliferation arresting cells in the G1 phase of cell cycle (45).

\section{LncRNAs Regulating HMGA Proteins}

Long non-coding RNAs are a class of transcribed RNA molecules ranging in length from $200 \mathrm{nt}$ to $\sim 100 \mathrm{~kb}$ and lacking proteincoding capability. Unlike mRNAs, which exhibit strong conservation across diverse species, lncRNAs are generally poorly conserved, they are preferentially expressed in tissue-specific manner and they can regulate the transcription, stability, or translation of protein-coding genes by different ways that have not been not fully clarified yet (46).

Among the lncRNAs, pseudogenes are a class of RNA molecules that have lost their coding potential because of premature or delayed stop codons, deletions/insertions, and frameshift mutations that abrogate translation into functional proteins $(47,48)$.

They are classified in processed, if they were generated by retro-transposition of the corresponding protein-coding mRNA, or unprocessed, if they arise by gene duplication and then acquire mutations making them non-functional. Since processed pseudogenes share $5^{\prime}$ and $3^{\prime}$ UTR sequences with their ancestral genes, they can exert regulatory control of parental gene expression by competing for the same miRNAs (49).

Recently, two HMGA1 non-coding processed pseudogenes, HMGA1P6 and HMGA1P7, have been identified and characterized. Both HMGA1P6 and HMGA1P7 have conserved seed matches for miRNAs targeting HMGA1 and HMGA2 genes and they work as competitive endogenous RNA (ceRNA), thereby protecting HMGAs from the inhibition of protein expression by miRNAs. Consistently, HMGA1 pseudogenes (Ps) also show oncogenic activity by inhibiting apoptosis and increasing cell proliferation and migration $(50,51)$. Moreover, a direct correlation between HMGA1 and HMGA1Ps expression in a set of human pituitary tumors, including somatotroph adenomas and NFPA or gonadotroph FSH-LH tumors has been found. Functional studies have also demonstrated that both pseudogenes affect pituitary cell proliferation and migration. Indeed, overexpression of HMGA1P6 or HMGA1P7 reduced the growth rate of the pituitary cell line AtT20 and, consistently with the role of HMGA1 in promoting cell migration, their enforced expression increases the 
migration of the same cells, thus indicating that HMGA1 pseudogene overexpression contributes to pituitary tumor development, thereby disclosing an additional mechanism responsible for the increased expression of HMGA1 in PAs (52).

A recent analysis of lncRNA expression in gonadotroph adenomas has unveiled a list of differentially regulated lncRNAs. Interestingly, among the most upregulated lncRNAs (fold-change 53,18 compared with normal pituitary) we found the RPSAP52 (ribosomal protein SA pseudogene 52) gene, which is the natural antisense of the HMGA2 gene. It belongs to the category of the antisense lncRNAs, which are transcribed from the antisense strand and partially overlap with the coding strand, and thereby regulate expression of corresponding coding genes at transcriptional or post-transcriptional level through various mechanisms (53). Recent results demonstrate that the enforced expression of RPSAP52 is able to increase the HMGA2 protein level, induces cancer cell proliferation, and promotes cell cycle progression. Conversely, downregulation of HMGA2 protein and decreased proliferation rate of cancer cells were observed when RPSAP52 expression was inhibited by antisense oligonucleotides. Then, RPSAP52 is able to positively regulate the associated HMGA2 gene, promoting its oncogenic activity, by mechanisms that are currently under investigation.

\section{Conclusion and Perspective}

Taken together, the data overviewed here highlight the critical role of HMGA1 and HMGA2 overexpression in the onset of PAs. Moreover, the most recent studies evidence that aberrant HMGA protein levels in PAs are also sustained by epigenetic mechanisms. Indeed, it has been demonstrated that a set of miRNAs, constantly and drastically downregulated in PAs, are able to target both the $H M G A$ genes. Interestingly, some of these miRNAs target also E2F1 whose activation, at least in animal models, is a critical step for PA development in transgenic mice overexpressing the HMGA genes.

Very recently, it has been shown that two HMGA1 pseudogenes are overexpressed in PAs. Their overexpression protects both the HMGA mRNAs from the miRNA-mediated downregulation of $H M G A$ genes. Functional studies support the role of miRNA downregulation and HMGA1 pseudogene overexpression in pituitary tumorigenesis. In fact, miRNA-restoration reduces the proliferation rate of pituitary cell lines, with an increased G1 phase

\section{References}

1. Ezzat S, Asa SL, Couldwell WT, Barr CE, Dodge WE, Vance ML, et al. The prevalence of pituitary adenomas: a systematic review. Cancer (2004) 101:613-9. doi:10.1002/cncr.20412

2. Kopczak A, Renner U, Karl Stalla G. Advances in understanding pituitary tumors. F1000Prime Rep (2014) 6:5. doi:10.12703/P6-5

3. Trouillas J. In search of a prognostic classification of endocrine pituitary tumors. Endocr Pathol (2014) 25:124-32. doi:10.1007/s12022-014-9322-y

4. Melmed S. Pathogenesis of pituitary tumors. Nat Rev Endocrinol (2011) 7:257-66. doi:10.1038/nrendo.2011.40

5. Gadelha MR, Trivellin G, Hernández Ramírez LC, Korbonits M. Genetics of pituitary adenomas. Front Horm Res (2013) 41:111-40. doi:10.1159/ 000345673

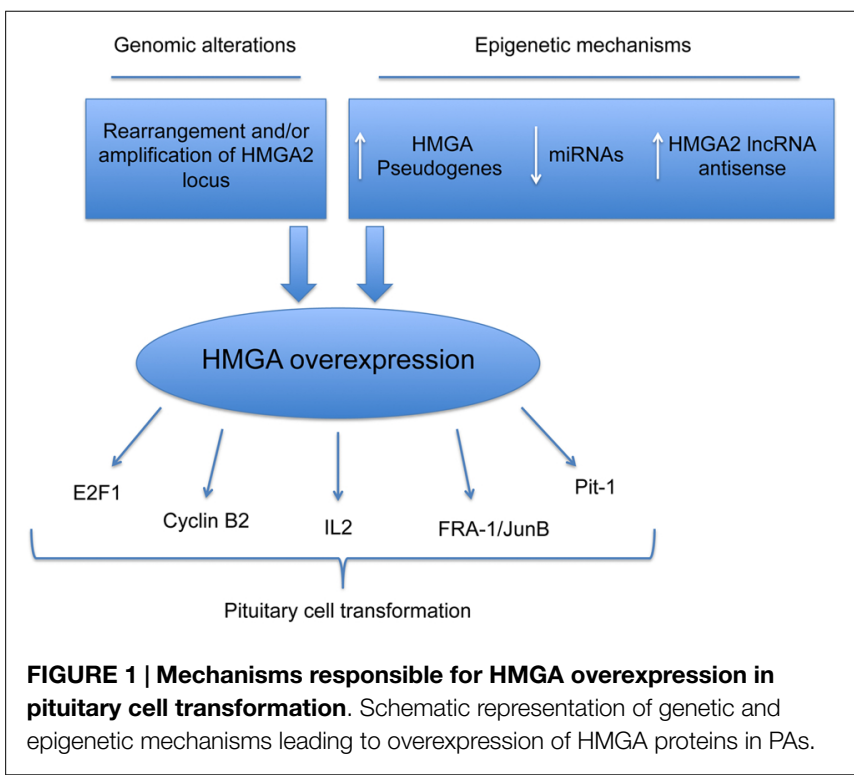

of cell cycle, accordingly with a reduction of the HMGA expression. Conversely, HMGA1 pseudogene overexpression, acting as ceRNA and protecting HMGAs from the inhibition of miRNAs, promotes the HMGA oncogenic activity. Finally, preliminary studies showed a drastic upregulation in PAs of the RPSAP52, the lncRNA antisense of HMGA2, which also leads to increased HMGA2 protein levels (Figure 1).

Then, all these data support an innovative therapy of the invasive PAs, based on the impairment of the HMGA protein function, that could not only be achieved directly, by the use of specific short interfering RNAs and/or drugs able to impair their activity, such as trabectedin (54), but also indirectly, restoring the expression of the HMGA-targeting miRNAs. Since miRNAs are able to target more than one gene that often code for proteins that are involved in the same or correlated pathways this last approach might represent an additional advantage for the antineoplastic therapy.

\section{Acknowledgments}

This work has been supported by grants from AIRC (IG 11477), P.O.R. Campania FSE 2007-2013 - Progetto CREMe CUP B25B09000050007 and CNR Epigenomics Flagship Project "EPIGEN."

6. Pei L, Melmed S. Isolation and characterization of a pituitary tumortransforming gene (PTTG). Mol Endocrinol (1997) 11:433-41. doi:10.1210/ mend.11.4.9911

7. Yu R, Melmed S. Pituitary tumor transforming gene: an update. Front Horm Res (2004) 32:175-85.

8. Zhang X, Sun H, Danila DC, Johnson SR, Zhou Y, Swearingen B, et al. Loss of expression of GADD45 gamma, a growth inhibitory gene, in human pituitary adenomas: implications for tumorigenesis. J Clin Endocrinol Metab (2002) 87:1262-7. doi:10.1210/jc.87.3.1262

9. Quereda V, Malumbres M. Cell cycle control of pituitary development and disease. J Mol Endocrinol (2009) 42:75-86. doi:10.1677/JME-08-0146

10. Jacks T, Fazeli A, Schmitt EM, Bronson RT, Goodell MA, Weinberg RA. Effects of an Rb mutation in the mouse. Nature (1992) 359:295-300. doi:10.1038/ $359295 \mathrm{a} 0$ 
11. Fero ML, Rivkin M, Tasch M, Porter P, Carow CE, Firpo E, et al. A syndrome of multiorgan hyperplasia with features of gigantism, tumorigenesis, and female sterility in p27Kip1-deficient mice. Cell (1996) 85:733-44. doi:10.1016/ S0092-8674(00)81239-8

12. Franklin DS, Godfrey VL, Lee H, Kovalev GI, Schoonhoven R, Chen-Kiang S, et al. CDK inhibitors p18(INK4c) and p27(Kip1) mediate two separate pathways to collaboratively suppress pituitary tumorigenesis. Genes Dev (1998) 12:2899-911. doi:10.1101/gad.12.18.2899

13. Reincke M, Sbiera S, Hayakawa A, Theodoropoulou M, Osswald A, Beuschlein F, et al. Mutations in the deubiquitinase gene USP8 cause Cushing's disease. Nat Genet (2015) 47(1):31-8. doi:10.1038/ng.3166

14. Ma Z-Y, Song Z-J, Chen J-H, Wang Y-F, Li S-Q, Zhou L-F, et al. Recurrent gainof-function USP8 mutations in Cushing's disease. Cell Res (2015) 25(3):306-17. doi: $10.1038 /$ cr.2015.20

15. Reeves R, Nissen MS. The A.T-DNA-binding domain of mammalian high mobility group I chromosomal proteins. A novel peptide motif for recognizing DNA structure. J Biol Chem (1990) 265:8573-82.

16. Abdulkadir SA, Krishna S, Thanos D, Maniatis T, Strominger JL, Ono SJ. Functional roles of the transcription factor Oct-2A and the high mobility group protein I/Y in HLA-DRA gene expression. J Exp Med (1995) 182:487-500. doi:10.1084/jem.182.2.487

17. Lehming N, Thanos D, Brickman JM, Ma J, Maniatis T, Ptashne M. An HMGlike protein that can switch a transcriptional activator to a repressor. Nature (1994) 371:175-9. doi:10.1038/371175a0

18. Thanos D, Du W, Maniatis T. The high mobility group protein HMG I(Y) is an essential structural component of a virus-inducible enhancer complex. Cold Spring Harb Symp Quant Biol (1993) 58:73-81. doi:10.1101/SQB.1993.058. 01.011

19. Fedele M, Fusco A. HMGA and cancer. Biochim Biophys Acta (2010) 1799:48-54. doi:10.1016/j.bbagrm.2009.11.007

20. Berlingieri MT, Manfioletti G, Santoro M, Bandiera A, Visconti R, Giancotti V, et al. Inhibition of HMGI-C protein synthesis suppresses retrovirally induced neoplastic transformation of rat thyroid cells. Mol Cell Biol (1995) 15: 1545-53.

21. Wood LJ, Maher JF, Bunton TE, Resar LMS. The oncogenic properties of the HMG-I gene family the oncogenic properties of the HMG-I gene family 1. Cancer Res (2000) 60(15):4256-61.

22. Baldassarre G, Fedele M, Battista S, Vecchione A, Klein-Szanto AJ, Santoro $\mathrm{M}$, et al. Onset of natural killer cell lymphomas in transgenic mice carrying a truncated HMGI-C gene by the chronic stimulation of the IL-2 and IL15 pathway. Proc Natl Acad Sci U S A (2001) 98:7970-5. doi:10.1073/pnas. 141224998

23. Fedele M, Battista S, Kenyon L, Baldassarre G, Fidanza V, Klein-Szanto AJP, et al. Overexpression of the HMGA2 gene in transgenic mice leads to the onset of pituitary adenomas. Oncogene (2002) 21:3190-8. doi:10.1038/sj.onc. 1205428

24. Fedele M, Pentimalli F, Baldassarre G, Battista S, Klein-Szanto AJP, Kenyon $\mathrm{L}$, et al. Transgenic mice overexpressing the wild-type form of the HMGA1 gene develop mixed growth hormone/prolactin cell pituitary adenomas and natural killer cell lymphomas. Oncogene (2005) 24:3427-35. doi:10.1038/sj.onc. 1208501

25. Ashar HR, Fejzo MS, Tkachenko A, Zhou X, Fletcher JA, Weremowicz S, et al. Disruption of the architectural factor HMGI-C: DNA-binding AT hook motifs fused in lipomas to distinct transcriptional regulatory domains. Cell (1995) 82:57-65. doi:10.1016/0092-8674(95)90052-7

26. Schoenmakers EF, Wanschura S, Mols R, Bullerdiek J, Van den Berghe H, Van de Ven WJ. Recurrent rearrangements in the high mobility group protein gene, HMGI-C, in benign mesenchymal tumours. Nat Genet (1995) 10:436-44. doi:10.1038/ng0895-436

27. Finelli P, Pierantoni GM, Giardino D, Losa M, Rodeschini O, Fedele M, et al. The high mobility group A2 gene is amplified and overexpressed in human prolactinomas. Cancer Res (2002) 62:2398-405.

28. Pierantoni GM, Finelli P, Valtorta E, Giardino D, Rodeschini O, Esposito F, et al. High-mobility group A2 gene expression is frequently induced in non-functioning pituitary adenomas (NFPAs), even in the absence of chromosome 12 polysomy. Endocr Relat Cancer (2005) 12:867-74. doi:10.1677/erc.1. 01049
29. Evans C-O, Moreno CS, Zhan X, McCabe MT, Vertino PM, Desiderio DM, et al. Molecular pathogenesis of human prolactinomas identified by gene expression profiling, RT-qPCR, and proteomic analyses. Pituitary (2008) 11:231-45. doi:10.1007/s11102-007-0082-2

30. De Martino I, Visone R, Wierinckx A, Palmieri D, Ferraro A, Cappabianca $\mathrm{P}$, et al. HMGA proteins up-regulate CCNB2 gene in mouse and human pituitary adenomas. Cancer Res (2009) 69:1844-50. doi:10.1158/0008-5472. CAN-08-4133

31. Šteno A, Bocko J, Rychlý B, Chorváth M, Celec P, Fabian M, et al. Nonfunctioning pituitary adenomas: association of Ki-67 and HMGA-1 labeling indices with residual tumor growth. Acta Neurochir (Wien) (2014) 156:451-61. doi:10.1007/s00701-014-1993-0

32. Fedele M, Visone R, De Martino I, Troncone G, Palmieri D, Battista S, et al. HMGA2 induces pituitary tumorigenesis by enhancing E2F1 activity. Cancer Cell (2006) 9:459-71. doi:10.1016/j.ccr.2006.04.024

33. Vallone D, Battista S, Pierantoni GM, Fedele M, Casalino L, Santoro M, et al. Neoplastic transformation of rat thyroid cells requires the junB and fra- 1 gene induction which is dependent on the HMGI-C gene product. EMBO J (1997) 16:5310-21. doi:10.1093/emboj/16.17.5310

34. Palmieri D, Valentino T, De Martino I, Esposito F, Cappabianca P, Wierinckx A, et al. PIT1 upregulation by HMGA proteins has a role in pituitary tumorigenesis. Endocr Relat Cancer (2012) 19:123-35. doi:10.1530/ERC-11-0135

35. Fedele M, Palmieri D, Fusco A. HMGA2: a pituitary tumour subtypespecific oncogene? Mol Cell Endocrinol (2010) 326:19-24. doi:10.1016/j.mce. 2010.03.019

36. Wang EL, Qian ZR, Rahman MM, Yoshimoto K, Yamada S, Kudo E, et al. Increased expression of HMGA1 correlates with tumour invasiveness and proliferation in human pituitary adenomas. Histopathology (2010) 56:501-9. doi:10.1111/j.1365-2559.2010.03495.x

37. Dermitzakis ET, Reymond A, Antonarakis SE. Conserved non-genic sequences - an unexpected feature of mammalian genomes. Nat Rev Genet (2005) 6:151-7. doi:10.1038/nrg1527

38. Bartel DP. microRNAs: target recognition and regulatory functions. Cell (2009) 136:215-33. doi:10.1016/j.cell.2009.01.002

39. Bentwich I. Prediction and validation of microRNAs and their targets. FEBS Lett (2005) 579:5904-10. doi:10.1016/j.febslet.2005.09.040

40. Dong H, Lei J, Ding L, Wen Y, Ju H, Zhang X. microRNA: function, detection, and bioanalysis. Chem Rev (2013) 113:6207-33. doi:10.1021/cr300362f

41. Di Leva G, Garofalo M, Croce CM. microRNAs in cancer. Annu Rev Pathol (2014) 9:287-314. doi:10.1146/annurev-pathol-012513-104715

42. Qian ZR, Asa SL, Siomi H, Siomi MC, Yoshimoto K, Yamada S, et al. Overexpression of HMGA2 relates to reduction of the let-7 and its relationship to clinicopathological features in pituitary adenomas. Mod Pathol (2009) 22:431-41. doi:10.1038/modpathol.2008.202

43. Palmieri D, D’Angelo D, Valentino T, De Martino I, Ferraro A, Wierinckx A, et al. Downregulation of HMGA-targeting microRNAs has a critical role in human pituitary tumorigenesis. Oncogene (2012) 31:3857-65. doi:10.1038/onc. 2011.557

44. D’Angelo D, Palmieri D, Mussnich P, Roche M, Wierinckx A, Raverot G, et al. Altered microRNA expression profile in human pituitary GH adenomas: downregulation of miRNA targeting HMGA1, HMGA2, and E2F1. J Clin Endocrinol Metab (2012) 97:E1128-38. doi:10.1210/jc.2011-3482

45. Leone V, Langella C, D’Angelo D, Mussnich P, Wierinckx A, Terracciano L, et al. miR-23b and miR-130b expression is downregulated in pituitary adenomas. Mol Cell Endocrinol (2014) 390:1-7. doi:10.1016/j.mce.2014.03.002

46. Gutschner T, Diederichs S. The hallmarks of cancer: a long non-coding RNA point of view. RNA Biol (2012) 9:703-19. doi:10.4161/rna.20481

47. Mighell AJ, Smith NR, Robinson PA, Markham AF. Vertebrate pseudogenes. FEBS Lett (2000) 468:109-14. doi:10.1016/S0014-5793(00)01199-6

48. Balakirev ES, Ayala FJ. Pseudogenes: are they “junk" or functional DNA? Annu Rev Genet (2003) 37:123-51. doi:10.1146/annurev.genet.37.040103.103949

49. Poliseno L, Salmena L, Zhang J, Carver B, Haveman WJ, Pandolfi PP. A codingindependent function of gene and pseudogene mRNAs regulates tumour biology. Nature (2010) 465:1033-8. doi:10.1038/nature09144

50. Esposito F, De Martino M, Petti MG, Forzati F, Tornincasa M, Federico A, et al. HMGA 1 pseudogenes as candidate proto-oncogenic competitive endogenous RNAs. Oncotarget (2014) 5(18):8341-54. 
51. Esposito F, De Martino M, D’Angelo D, Mussnich P, Raverot G, JaffrainRea ML, et al. HMGA1-pseudogene expression is induced in human pituitary tumors. Cell Cycle (2015) 14(9):1471-5. doi:10.1080/15384101.2015. 1021520

52. Esposito F, De Martino M, Forzati F, Fusco A. HMGA1-pseudogene overexpression contributes to cancer progression. Cell Cycle (2014) 13:3636-9. doi:10. $4161 / 15384101.2014 .974440$

53. Kung JTY, Colognori D, Lee JT. Long noncoding RNAs: past, present, and future. Genetics (2013) 193:651-69. doi:10.1534/genetics.112.146704

54. D’Angelo D, Borbone E, Palmieri D, Uboldi S, Esposito F, Frapolli R, et al. The impairment of the high mobility group A (HMGA) protein function contributes to the anticancer activity of trabectedin. Eur J Cancer (2013) 49:1142-51. doi:10. 1016/j.ejca.2012.10.014
Conflict of Interest Statement: The authors declare that the research was conducted in the absence of any commercial or financial relationships that could be construed as a potential conflict of interest. The Review Editor Rosa Marina Melillo declares that, despite being affiliated to the same institution as the authors Daniela D'Angelo, Francesco Esposito, and Alfredo Fusco, the review process was handled objectively and no conflict of interest exists.

Copyright (C) 2015 D'Angelo, Esposito and Fusco. This is an open-access article distributed under the terms of the Creative Commons Attribution License (CC BY). The use, distribution or reproduction in other forums is permitted, provided the original author(s) or licensor are credited and that the original publication in this journal is cited, in accordance with accepted academic practice. No use, distribution or reproduction is permitted which does not comply with these terms. 